\title{
OUTRAS FALAS POSSÍVEIS: A EMERGÊNCIA DA COMUNICAÇÃO POPULAR COLABORATIVA COMO ESTRATÉGIA EDUCATIVA
}

\author{
Henrique Oliveira de ARAÚJO ${ }^{1}$
}

Antenor Rita GOMES ${ }^{2}$

RESUMO: Num mundo em que as "agendas discursivas" permanecem, em grande parte, sob a tutela de poucos, a comunicação popular colaborativa surge como uma forma de resistência educativa: como um "golpe" contra o olhar panóptico dominante da nossa sociedade. O presente artigo defende que um novo fazer comunicacional é possível e, partindo de uma abordagem outra, se refere a uma comunicação educacional, de "outras falas possíveis", construída através de um modelo participativo. Uma comunicação que, como defende Serge Desgangné (2007), tem o potencial de oferecer uma participação aos sujeitos em um fazer comunicativo mais aberto, onde não detentores dos "meios de produção" dos discursos aceitos se transformam em de cocomunicadores e co-construtores de suas próprias oportunidades.

PALAVRAS-CHAVE: Educação. Práticas educacionais. Comunicação popular. Comunicação colaborativa.

\section{INTRODUÇÃO}

Há muito se sabe que a comunicação humana não é linear. Diferente de uma linha de transmissão asséptica, inodora, amorfa, entre emissor e receptor, o ato comunicativo é complexo e se constitui num tecido inextrincável que, parafraseando Edgar Morin (2005), é um construto heterogêneo, repleto de ações, retroações, influências, interpretações.

Essa não linearidade, suas desordens e imprevisibilidades fazem com que deixemos ainda mais para trás a antiga concepção matemática da comunicação. Não estamos mais diante de produtores e recebedores de conteúdos; não temos mais um processo comunicativo de papéis fixos, marcado somente pelos oligopólios, ou por "dominadores" culturais. Mesmo nosso entendimento não tendo se desprendido da fábula globalizadora, brilhantemente identificada por Milton Santos (2011) no século

1 Mestrando em Educação e Diversidade. UNEB - Universidade do Estado da Bahia. Departamento de Ciências Humanas IV. Serrinha - BA - Brasil. 48700-000. Graduado em Comunicação Social pela Universidade Estadual do Sudoeste da Bahia. Atualmente coordena a equipe de comunicação popular do Centro de Assessoria do Assuruá - henrique.daraujo@gmail.com

${ }^{2}$ Professor do Mestrado Profissional em Educação e Diversidade - MPED e do Mestrado em Educação Cultura e Territórios Semiáridos - PPGESA. UNEB - Universidade do Estado da Bahia. Departamento de Ciências Humanas IV. Serrinha - BA - Brasil. 48700-000. Doutor em Educação. UFBA - Universidade Federal da Bahia - argomes@uneb.br 
passado, descortinamos, em meio aos turbilhões e interconexões, capitaneadas principalmente pela internet e pelas novas redes, um momento de "rebeldia comunicativa", em que não mais sabemos identificar com balizas visíveis o que é "só audiência" e o que é "só produção".

Há na contemporaneidade uma mistura comunicativa, talvez os primeiros passos para uma desconstrução comunicativa horizontalizadora, que modifica o sistema como um todo e faz estremecer os cânones de um processo historicamente vertical, moldado por um antigo conhecimento simplificador, "triunfante" (ADORNO; HORKHEIMER, 1985). Um conhecimento entalhado pelo enquadramento mais raso dos cálculos, das disjunções e das reduções.

O presente artigo apresenta uma reflexão sobre a possibilidade da construção de uma comunicação popular colaborativa e vinculada a um processo complexo e multifacetado de formação educativa. Dessa forma, proporemos a seguir uma fazer comunicacional e educativo que se conforma como uma reação de qualidade política: uma vez que parte de uma posição epistemológica construída para, diferente da educação mercadológica, valorizar os pontos de vista, as nuances e identidades dos sujeitos.

Sobre as bases de uma démarche colaborativa nossa reflexão se desloca para baixo - vai até o rés do chão, para considerar de forma mais profunda e honesta a possibilidade de construção que valorize função de professores e alunos da educação básica na elaboração de uma proposta comunicativa popular, democrática e contextualizada. A comunicação colaborativa, que nesse trabalho se propõe, transporta a abordagem defendida por Desgangné (2007) para o fazer da comunicação popular.

Mais especificamente, propomos ser possível a construção de uma comunicação sobre as bases dos Movimentos socais, dentro do contexto escolar a partir do fio condutor da colaboração enquanto ordem epistemológica e metodológica. Para tanto retomamos a dimensão da co-construção enquanto conceito que enxerga os sujeitos da realidade escolar não como meros recebedores de conteúdo, como mas "atores sociais competentes" capazes de controlar e refletir acerca do seu agir (DESGANGNÈ, 2007).

Daí defendermos a colaboração para a construção de conhecimentos ligados à prática da comunicação popular no contexto da escola. Acreditamos que, ao transpor a abordagem colaborativa para o âmbito da comunicação popular horizontal estaremos semeando um terreno ainda pouco trabalhado da relação entre comunicação e educação. A concepção de sujeitos co-construtores de uma comunicação com conteúdos 
contextualizados e críticos, faz com que tais indivíduos atuem diretamente na construção das suas realidades, não sendo instrumentos ou fontes de um sistema educativo e comunicativo estrangeiros, deslocados.

Partimos, pois, do entendimento que os sujeitos da educação são mais do que meros executores e ouvintes de um "[...] saber-ensinar e saber-aprender construído por outros (relação com o saber de tipo aplicado, por oposição à relação com o saber do tipo contextualizado)" (DESGANGNÉ, 2007, p. 25). Dessa forma, buscamos romper com a carapaça da primeira aparência de homogeneidade que a totalidade escolar apresenta e propor uma atividade de ruptura. Como definiu Ferrara (1993), tal comunicação, guarda a possibilidade de se constituir como um "lugar informado": um lugar onde a informação se efetiva enquanto produtora de aprendizagens e comportamentos dentro do "Espaço de Informação" totalizado e aparentemente homogeneizado que é a escola.

\section{O PENSAMENTO COMUNICATIVO SIMPLIFICADOR}

Para Edgar Morin (2005) o pensamento contemporâneo padece de uma patologia simplificadora. O desenvolvimento das ciências, sob a égide do cartesianismo e sua tendência em reduzir a realidade em partes ordenadas e organizadas por leis pretensamente universais, criou um determinismo que se queria "absoluto e perpétuo". A busca por uma substância elementar, uma forma original, simples, que fosse regida por uma lei única, deturpou nosso entendimento do mundo e escamoteou a complexidade dos fenômenos naturais.

No entanto, tal caminho redutor se mostrou cada vez mais insuficiente: quanto mais se separam (disjunção) e se reduzem os elementos, mais relações e interconexões são encontradas. As ciências físicas, por exemplo, ao encontrar o átomo, se depararam com outras tantas relações complexas que o perfazem. Nas ciências sociais, os pesquisadores positivistas, ao se depararem com a realidade individual, perceberam que a mesma não se isola do infindável jogo de relações e interações sociais que a entrecortam.

Tanto os fenômenos naturais, quanto os sociais partem e chegam numa infinita complexidade, que engloba não só sistemas ordenados ao final, mas um emaranhado de desordens nos entremeios: 
Descobriu-se no universo físico um princípio hemorrágico de degradação e de desordem (segundo princípio da termodinâmica); depois, no que se supunha ser o lugar da simplicidade física e lógica, descobriu-se a extrema complexidade microfísica; a partícula não é um primeiro tijolo, mas uma fronteira sobre uma complexidade talvez inconcebível; o cosmos não é um maquina perfeita, mas um processo em vias de desintegração e de organização ao mesmo tempo (MORIN, 2005, p.14).

No entanto, o pensamento simplificador, de tradição cartesiana, nos levou tanto no entendimento dos processos comunicativos e educativos, quanto no tocante à própria interpretação do mundo - a uma "inteligência cega" que nos impele a rejeitar as realidades interacionais, e desprezar as transformações interligadas de sujeitos e objetos na construção do conhecimento. Buscamos assim, uma edificação de saberes assépticos, simplificados, lineares, que se calcam no isolamento dos observadores (res cogitans) e da coisa observada (res extensa).

Um exemplo marcante desse movimento de homogeneização dentro da tradição da communication research é o modelo comunicativo formulado por Laswell e resgatado por Mauro Wolf (1999) em seu panorama teórico. Segundo Wolf, a fórmula de Laswell se ancora na tradição de pesquisa da teoria hipodérmica ${ }^{3}$ e parte do pressuposto que a comunicação é uma iniciativa do comunicador (enunciador) para que os efeitos recaiam exclusivamente sobre o público (receptor).

Segundo esse modelo, é o emissor ativo que produz o estímulo destinado a uma massa passiva de destinatários, para gerar um objetivo estabelecido e produzir um estímulo, "um determinado efeito", que, por essência, é observável, passível de avaliação.

A ideia preconizada por Laswell é a de que os objetivos comunicacionais geram um "comportamento" no público:

Este [comportamento] está sistematicamente relacionado com o conteúdo da mensagem. Consequentemente, a análise do conteúdo apresenta-se como o instrumento para inferir os objetivos de manipulação dos emissores e os únicos efeitos que tal modelo torna pertinentes são os que podem ser observados, isto é, os que podem ser associados a uma modificação, a uma mudança de comportamentos, atitudes, opiniões, etc. [...] os papéis do comunicador e destinatário surgem isolados, independentes das relações sociais, situacionais e

\footnotetext{
${ }^{3}$ A teoria Hipodérmica da comunicação surgiu no período compreendido entre as duas guerras mundiais, quando se iniciou difusão em larga escalar das chamadas "comunicações de massa". Segundo esse entendimento cada pessoa, componente do público, é "pessoal e diretamente" atingido pela mensagem transmitida (WOLF, 1999).
} 
culturais em que os processos comunicativos se realizam, mas que o modelo em si não contempla: os efeitos dizem respeito a destinatários atomizados, isolados. (SCHULZ, 1982 apud WOLF, 1999, p.10).

Sob esse modelo redutor, vemos emergir uma inteligência e uma comunicação cegas - guiadas por uma visão unidimensional que mutila e descarta as desordens e pretendem enquadrar emissores e receptores num modelo homogeneizador, incapaz de conceber a complexidade dos construtos antropossociais e da relação intrínseca do todo com as partes, dos sujeitos com os objetos, dos receptores com os conteúdos e, podemos agora dizer, dos sujeitos comunicacionais com a produção desses conteúdos.

Infelizmente, pela visão mutiladora e unidimensional, paga-se bem caro nos fenômenos humanos: a mutilação corta na carne, verte o sangue, expande o sofrimento. A incapacidade de conceber a complexidade da realidade antropossocial, em sua microdimensão (o ser individual) e em sua macrodimensão (o conjunto da humanidade planetária), conduz a infinitas tragédias e nos conduz à tragédia suprema. (MORIN, 2005, p.13).

$\mathrm{Na}$ construção da comunicação de massas, guia mor de uma "unidimensionalidade social”, tal "tragédia" (essa visão mecanicista e antidemocrática) ganhou contornos decisivos. O modelo teórico de Laswell, para muitos enterrado na história da communication research, parece ter sido resgatado para estabelecer lugares sociais rígidos, centrados naquilo que se chama de "produção e emissão" de mensagens, e na manipulação de conteúdos, conhecimentos e influências.

No Brasil, assim como na América Latina, criou-se uma comunicação de massa dominante, persuasiva, mercantilista e pouco participativa. Sob esse sistema fabricaramse verdades, interpretações dominantes, verdadeiras "vontades de verdade", que como nos ensina Michel Foucault (1999), estão ligados aos desejos e poderes socialmente constituídos.

Para Luis Ramiro Beltran (1981), esse movimento comunicativo se baseou num sistema de dominação vertical, consolidado de cima para baixo, onde oligarquias recorreram (e ainda recorrem) aos meios de comunicação para “dominar os sem poder".

O que ocorre seguidamente sob o nome de comunicação é pouco mais do que um monólogo dominante em benefício do iniciador do processo. A retroalimentação ${ }^{4}$ não é empregada para proporcionar a

${ }^{4}$ O conceito de retroalimentação para Beltran (1981, p.34) é uma feição importantíssima do diálogo multidirecional equilibrado. É pela retroalimentação que, segundo o autor, "todas as pessoas, e cada uma 
oportunidade de diálogo autêntico. O receptor das mensagens é passivo e está submetido, uma vez que quase nunca se lhe dá a oportunidade adequada para atuar também como verdadeiro e livre emissor; seu papel consiste em escutar e obedecer. Tão vertical, assimétrica e quase-autoritária relação constitui, no meu modo de ver, uma forma antidemocrática de comunicação. [...] devemos ser capazes de construir um novo conceito de comunicação - um modelo humanizado, não-elitista, democrático e não-mercantilizado. (BELTRAN, 1981, p. 23).

Tal verticalização comunicativa foi embasada numa concepção de cultura que, como sinalizou Michel de Certeau (1995), se elitizou ao longo da história. Os que dominaram, no Brasil e na América Latina os meios de produção da comunicação de massas concorreram para um movimento de intelectualização da "cultura" pasteurizada, localizada na ponta de cima dos processos comunicacionais. Negaram, assim, a pluralidade comunicativa e cultural da sociedade, seus os entremeios foram escamoteados, a musculatura básica da comunicação humana se escondeu abaixo de quilos de um tecido adiposo alienante.

\section{COMPLEXIDADE, COMUNICAÇÃO COLABORATIVA E EDUCAÇÃO}

Numa de suas palestras proferidas no Brasil, Boventura de Sousa Santos (ABONG, 2004), afirmou que vivemos numa complexa sociedade-conhecimento. Segundo o professor, apesar de estarmos imersos em contextos sociais repletos de significados e mensagens, diversas mediações nos levam construir um modelo de conhecimento "aceito". Tais modelos tornam rígida a "realidade" e impedem os sujeitos sociais de construir uma concepção mais ampliada do mundo. Criamos, ao produzir e reproduzir nossas fontes oficiais de saber, uma racionalidade míope, calcada num modelo que "contrai o presente" e faz parecer que o que vivemos hoje, nas nossas relações microfísicas, seja menos importante que o contexto global.

Para Santos, "[...] a razão pela qual nós temos essa concepção de presente totalmente contraído, é porque a racionalidade que nos domina é uma racionalidade que restringe a experiência do presente" (ABONG, 2004, p.42). Vivemos sobre os ombros de uma racionalização que não valoriza o conhecimento de mundo dos sujeitos sociais enquanto tais e, muito menos, aceita o saber criado por aqueles que são assimétricos aos discursos dominantes. É como se esse "conhecimento do agora" fosse parte de 
experiências de segunda classe que não merecem os olhos "sérios" do saber científico. Essas experiências reais, conformadoras da complexidade do presente, são postas de lado em nome de uma rede de "monoculturas" que dominam a racionalidade socialmente instituída.

Tal visão se constitui numa intensa distorção. Afinal, conforme indicamos em outro momento desse texto, a sociedade não pode ser encarada cartesianamente e, muitos menos, podemos dirimir sua complexidade. Nesse sentido, lembramos as primeiras discussões da antropologia cultural americana, capitaneadas pelo professor Frantz Boas (2005), para quem, ao se propor um entendimento para as ciências sociais, a cultura não poderia ser estudada de maneira rígida, em "tons monocromáticos". A cultura não é monolítica. Ela é diversa desde a sua gênese e é constituída de saberes interrelacionados, onde o indivíduo se insere dialeticamente.

[...] reconhecemos que o indivíduo só pode ser compreendido como parte da sociedade à qual pertence, e que a sociedade só pode ser compreendida com base nas interrelações dos indivíduos seus constituintes. [...] Os problemas das ciências sociais são desse modo facilmente definidos. Eles se referem às formas das reações dos indivíduos, isoladamente e em grupos, os estímulos externos, às interações entre eles próprios e às formas sociais produzidas por esses processos. (BOAS, 2005, p.53).

Porém, seja no tocante aos processos de formação dos sujeitos, seja em suas produções comunicativas, as monoculturas racionais se fazem presentes e tendem a construir uma "verdade"; um discurso socialmente aceito que escamoteia a diferença e embasa processos de exclusão, contribuindo para sedimentar àquilo que Roberto Sidnei Macedo (2009, p.77) chamou de “finalismo cartesiano". Um pensamento que desconsidera ou desvaloriza as práticas sociais fundantes: base das inúmeras interações e produções de sentido presentes nas sociedades humanas.

Tais entendimentos "finalistas" embasam as monoculturas do conhecimento, gerando um exército de "sombras". Uma rede de saberes e fazeres culturais, repleta de sujeitos ausentes, negados, marginalizados do seio do conhecimento e do reconhecimento.

Nesse sentido, para podermos propor uma alternativa, é fundamental que percebamos nosso "saber" como algo engendrado sobre as bases de um "conhecimento das ausências" que, como bem identificou Abdalaziz de Moura (2003), conformam uma interpretação que regurgita padrões e desestimula o desenvolvimento local como construtor de conhecimentos ligados à vida dos sujeitos e suas comunidades. Numa 
concepção Freireana (FREIRE, 2005), poderíamos dizer que a sociedade capitalista, da forma que ainda se desenha, despreza o saber dos oprimidos, não valorizando a intersubjetividade e a interação social.

A proposta de um conhecimento e de uma pedagogia centrada na práxis de homens e mulheres, que tende "ser mais" e ultrapassar sua condição servil em busca do rompimento com a cultura de dominação, precisa ultrapassar a concepção de conhecimento baseado na "não existência" ou na ausência do diferente, do assimétrico. Ela terá que percorrer o caminho contrário e se fundar nas experiências de uma cultura plural, criando uma "teoria nova do teatro social" antevista por Michel de Certeau (1995): onde espectadores se transformam em atores e a experiência simbólica se torna capaz de romper as fronteiras da emissão e recepção, se localizando nos entremeios do conhecimento e criando uma "ação simbolizadora comum" e colaborativa.

\section{COMUNICAÇÃO POPULAR COLABORATIVA COMO “ARTE DE FAZER”}

O padre Michel de Certeau (2013), em certo momento de sua vida intelectual, vai redimensionar seu entendimento sobre a cultura humana. Para ele não mais se deveria falar numa cultura plural, mas sim numa cultura múltipla. Para Certeau, num contexto cultural os sujeitos ordinários inventam e reinventam suas artes de fazer. Eles são individuais, específicos. Porém, estão relacionados com possibilidades sistêmicas. O todo, a sociedade enquanto construto anterior às pessoas, tem suas regras, seus modelos. Porém, os sujeitos, ativamente, fazem usos diferenciados dessas regras: eles as interconectam com suas experiências, seus contextos, suas interpretações. São bricoleurs procurando escapatórias, mesmo que temporárias, do "olhar panóptico" das regras sociais.

A Comunicação Popular é uma dessas estratégias, em que os sujeitos se articulam para inserir suas posições nas brechas ocasionadas pelo giro imperfeito dos faróis de vigilância do sistema. Estão muitas vezes nas sombras deixadas pelos relevos inesperados da comunicação de massas e, de lá, estabelecem seus "golpes”. Numa outra leitura, tal fazer comunicativo se faz uma rota de contrabando, como um caminho educativo que tem potencial para contribuir com o que Pedro Demo chamou de construção de cidadãos mais "críticos e criativos": 
Quando se afirma que o mercado precisa hoje de gente bem educada, na prática alega-se a necessidade de "treinamento" técnico, em particular em processos produtivos informatizados. Trata-se de qualidade formal típica, separada da qualidade política. Mesmo assim, cabe reconhecer este tipo de abertura, porque, pela Porta da qualidade formal, é possível contrabandear qualidade política, desde que se saiba criticamente que cidadania para o mercado é contrabando. (DEMO, 2000, p.17).

Para o autor, então, mais do que construir uma sociedade de competências técnicas (qualidade formal), é preciso que, através de suas "artes de fazer", os cidadãos se constituam em sua "qualidade política", criando um fazer, nas diversas esferas sociais, que os tornem capazes de se organizar com um mínimo de autonomia, deixando, por conseguinte a condição servil de massa de manobra para criar suas prórias oportunidades.

Nesse sentido acreditamos que a comunicação popular, enquanto prática horizontal e colaborativa de produção de mensagens e discursos, pode contribuir de formal decisiva nas práticas educacionais e, para além disso, se encaminhar para dar novo sentido ao conhecimento: um sentido não colonialista, não excludente e que sirva à cidadania popular e ao complexo processo de aprendizagem que é a vida.

Nesse âmbito, movimentos sociais e organizações do terceiro setor, como demonstra Mendonça (2004), se constituem como sujeitos políticos importantes. Pois, mesmo não se podendo aplicar uma visão única para todas essas Entidades, são tais organizações que, no Brasil mais viabilizam uma concepção de comunicação colaborativa - raiz de uma "constituição" crítica dos sujeitos sociais e que "[...] possibilita a emergência e a circulação de discursos dissidentes ou não hegemônicos" (MENDONÇA, 2004, p.50-51).

Uma nova proposta comunicativa parte, então, do pressuposto de que as transformações sociais e culturais estão ligadas à edificação dos discursos:

[...] as transformações sociais e culturais precisam acontecer também no plano dos discursos, por meio de alterações da agenda discursiva e da ampliação das falas possíveis, e pela inserção de novos temas e inclusão de certos segmentos sociais na produção de discursos. (MENDONÇA, 2004, p. 50).

Essa alteração nas "agendas discursivas", inserida nos diferentes âmbitos sociais; a emergência de "outras falas possíveis" são os elementos fundamentais para o "golpe" contra o olhar panóptico dominante que a comunicação popular colaborativa 
propõe (e que defendemos como uma alternativa ao fazer engessado dos mass media e da educação meramente formal). Partindo de uma abordagem outra, acreditamos ser possível se construir uma comunicação e um fazer educativo que, como defende Serge Desgangné (2007) em sua proposta metodológica, ofereça uma participação aos sujeitos, antes tidos como "receptores" passivos de mensagens pré-fabricadas.

Numa comunicação colaborativa os sujeitos envolvidos mesclam seus lugares de emissores e produtores. Trata-se de um fazer comunicativo e educativo aberto, onde não detentores dos "meios de produção" da comunicação de massa e da educação formalista se transformam, com o aporte das tecnologias cada vez mais acessíveis, em cocomunicadores e agentes de uma educação libertadora.

Ou seja, sob a face educacional de uma comunicação popular colaborativa os sujeitos se apoderam das técnicas comunicativas, através de processos educativos e pedagógicos, e participam executando desde as tarefas formais das técnicas da comunicação até a elaboração dos discursos veiculados. Dessa forma a comunicação popular colaborativa exige "a participação de co-construtores, ficando entendido que é a compreensão destes, no contexto do fenômeno explorado [...], o elemento essencial do processo" (DESGANGNÈ, 2007, p.18).

\section{COMUNICAÇÃO, LUTA SOCIAL E EDUCAÇÃO}

Tal proposta comunicativa, no entanto, só é possível se, na contramão dos mass media e de uma educação formalista, construamos uma comunicação de fato popular. Uma comunicação que represente, como defende Cicília Peruzzo (2006), uma forma alternativa de elaborar, distribuir e interpretar os discursos comunicacionais. Como já se sabe nas ciências da comunicação, tal movimento, principalmente no Brasil e na América Latina, tem suas bases fincadas nos movimentos populares dos anos de $1970 \mathrm{e}$ 1980 e se caracteriza como um processo que "emerge da ação dos grupos populares" (PERUZZO, 2006, p. 1).

Tais grupos que, num primeiro momento, se engajam para adquirir espaços e direitos nos campos "materiais" da política e do desenvolvimento social, são os primeiros a notar que os movimentos de resistência não se dão somente na luta por direitos formais ou por bens e serviços. Os movimentos e organizações sociais percebem que os processos simbólicos estão no centro dos "mecanismos" de 
desigualdade social, pois são eles, são os discursos dominantes, que determinam o embate social no campo da cultura.

[...] as lutas sociais, além de se travarem no campo político-legal, mostram ser tão ou mais necessárias no campo cultural, uma vez que será apenas a partir do momento em que os ganhos obtidos na conquista por direitos forem incluídos na vida cotidiana, em que comecem a fazer parte das práticas sociais e culturais dos indivíduos, que se pode reconhecer que houve, verdadeiramente, uma transformação. O campo simbólico no qual circulam os discursos que constroem a subjetividade, é também o campo no qual se desenrola uma disputa de sentidos que é parte da luta política e de um processo cultural e histórico para a fixação de sentidos em uma coletividade, [...] (MENDONÇA, 2004. p.51).

Em outras palavras a comunicação de viés popular se configura no seio da história e da estruturação dos movimentos e organizações populares. Tais Movimentos são os primeiros a sentir necessidade de criar canais próprios para "amplificar" seus discursos. Cria-se, a partir de uma leitura marxista, e através da ação direta da igreja católica e de suas Comunidades Eclesiais de Base (CEBs), a noção de comunicação participativa, capaz de unir "protagonistas" para criar uma proposta comunicativa "contra-hegemônica" e mais horizontal.

A luta contra a exclusão e as desigualdades ganha, dessa forma, novas arenas de batalha. E, cada vez mais, fica clara a necessidade dos movimentos populares se engajarem contra os discursos mercantilizados da comunicação de massas, numa marcante posição contra o processo de "colonização simbólica" impostas por uma construção cultural mutiladora e discriminatória.

Mais do que nunca, anseia-se por uma comunicação mais educativa, que, de forma mais democrática e aberta, construa e articule novos discursos, novas subjetividades e distribua a capacidade de enunciar a uma gama cada vez maior de pessoas silenciadas nas histórias e representações oficiais.

A partir dessa compreensão chega-se ao conceito de comunicação participativa como o processo social mediante o qual, protagonistas com interesses não antagônicos constroem em comum discursos que podem ser utilizados como luta para a modificação real de suas condições de existência, para a mudança das estruturas do poder econômico, político, social e cultural dominante e para a inversão das formas de comunicação vigentes. A comunicação participativa é uma pedagogia popular, um processo educativo que parte da análise da realidade, rechaça a ideologia dominante e mobiliza as classes 
populares para uma ação de transformação social. (SANTOS, 2002, p.5).

Partindo desses princípios a comunicação, enquanto processo social, ganha novas possibilidades. Agora, sob a luz de estudos sobre a comunicação de massas na América Latina, e o entendimento que os mass media, através de um profundo movimento histórico e social de concentração e controle, legitimam processos de exclusão e verticalização, ligou-se o fazer comunicativo popular a um conceito de mudança social. A esperança de transformação das condições sociais - motor de muitos movimentos organizados - se constituiu, dessa forma, como um "instrumento" material e, acima de tudo, simbólico para viabilizar a concepção de uma comunicação com participação popular.

Tal aspecto é fundamental para a proposta de uma comunicação de abordagem colaborativa e co-construtivista, pois são as bases (institucionais e políticas) para que se pense um fazer dialógico e engajado dentro de uma comunicação popular de cunho educativo, político, que se faz alternativa aos meios de massa e está fincada num processo democrático e progressista.

Entendendo esse viés popular e a interação constante com os movimentos e organizações populares, tal proposta comunicativa se transforma num "instrumento" através do qual as classes e sujeitos ditos subalternos podem externar seus discursos, valorizar suas concepções de mundo e concorrer para construir uma sociedade mais justa.

\section{CONCLUSÃO}

Não pretendemos aqui esgotar o assunto e muito menos traçar caminhos definitivos para uma comunicação popular, educativa e colaborativa. Porém, o que propomos é lançar um olhar um pouco mais detido sobre um fazer comunicativo que, partindo das contribuições da comunicação popular, pretende se construir de maneira horizontal e abre margem para uma contribuição mais efetiva de outros sujeitos (além dos jornalistas ou comunicadores profissionais).

Em outras palavras, ao adentrarmos numa realidade cultural complexa, propomos uma comunicação onde os diversos sujeitos envolvidos, em algum momento, sejam "co-construtores", dos produtos, dos discursos e do conhecimento. Para tanto, o 
modelo comunicativo que defendemos aqui, difere da comunicação popular clássica e bebe na fonte das pesquisas do campo educacional, adotando, para isso, uma abordagem colaborativa que, segundo Serge Desgangné (2007, p.9), ao pressupor a construção de conhecimentos ligados a uma dada prática profissional “[...] deve considerar o contexto real em que ela é atualizada e os seus componentes, em termos de limites e recursos existentes em situações reais, observando em que contribuem para a sua estruturação".

A comunicação colaborativa faz, assim, com que seja possível a emergência de "outras falas possíveis" - falas que não se fazem sem se considerar a compreensão que os próprios sujeitos da comunicação têm de sua realidade e do contexto prático, no interior do qual se desenvolve o fazer comunicativo.

Para além da atuação dos jornalistas e comunicadores profissionais (também inclusos no processo), a comunicação colaborativa busca co-construtores engajados num novo fazer comunicativo. São co-comunicadores atuantes, agentes de sua própria formação, encharcados com as experiências do presente, viventes do agora, que pensam e executam uma comunicação contextualizada em todas as suas etapas - da idealização à pós-produção ${ }^{5}$.

No entanto, todo esse processo (reconhecemos) só é possível se entendermos a comunicação popular colaborativa enquanto um fazer educacional. Afinal, na chamada Era da Informação, muitas são as encruzilhadas que a escola contemporânea terá que ultrapassar para que se volte a uma ação que leve em conta a sensibilidade e não a edificação de uma razão fria e asséptica. É para dialogar com uma "educação da incerteza" (SOARES, 2000), que a comunicação popular colaborativa deve existir. Pois, através dela, poderemos criar um novo processo de significação da realidade que se aproprie de forma mais inclusiva da história e da cultura em sua complexidade.

Essa nova comunicação está, assim, ligada a criação de um senso crítico diferenciado. Uma vez que, na era da informação, como bem definiu Martín-Barbero, mais do que uma racionalidade abstrata, técnica, os cidadãos exigem uma educação e uma comunicação que dialoguem e façam com que os sujeitos se coloquem de forma lúcida numa realidade múltipla e cada vez mais mutante.

\footnotetext{
$5 \mathrm{Na}$ abordagem colaborativa que defendemos é preciso delimitar o papel dos comunicadores profissionais (jornalistas ou não) dos outros sujeitos do processo. Pois, apesar de pressupormos uma coconstrução, os sujeitos sem uma devida formação técnica não podem ter, em sua atuação, uma mescla de todas as tarefas e etapas do trabalho. Em partes mais técnicas do processo, os comunicadores profissionais podem, sozinhos, assumir as tarefas. Por isso é preciso compreender bem o papel dos outros sujeitos nesse processo comunicativo, uma vez que o que será solicitado deles é sua participação, junto com os comunicadores profissionais, de um processo de construção de conteúdos e discursos comunicacionais.
} 
O cidadão de hoje pede ao sistema educativo que o capacite a ter acesso à multiplicidade de escritas, linguagens e discursos nos quais se produzem as decisões que o afetam, seja no campo de trabalho como no âmbito familiar, político e econômico. Isso significa que o cidadão deveria poder distinguir entre um telejornal independente e confiável e um outro que seja mero porta-voz de um partido ou de um grupo econômico, entre uma telenovela que esteja ligada ao seu país, inovando na linguagem e nos temas e uma telenovela repetitiva e simplória. Para tanto, necessitamos de uma escola na qual aprender a ler signifique aprender a distinguir, a tornar evidente, a ponderar e escolher onde e como se fortalecem os preconceitos ou se renovam as concepções que temos sobre política, família, cultura e sexualidade. (MARTÍN-BARBERO, 2000, p.58).

É esse senso crítico que a comunicação popular colaborativa quer fomentar, enquanto ato educativo transformador. Mais do que democratizar as técnicas de comunicação e permitir que os sujeitos façam seus produtos, o que propomos é uma formação de cidadãos que reflitam e intervenham sobre seu fazer cultural e, através de uma comunicação contra-hegemônica, que amplifica, através da co-construção comunicativa, discursos antes abafados pelo domínio dos mass media.

Nesse sentido, a escola ganha papel fundamental. Pois é lá que teremos plantada as primeiras sementes de um uso criativo e crítico dos meios de fazer e disseminar os novos discursos. Nenhuma outra instituição social poderá amplificar com maior força essa nova práxis de comunicação, pois é na escola onde se tornará possível que ultrapassemos a verticalidade das comunicações antigas, mutiladoras, e partamos de forma segura em direção a outra comunicação e educação: descentralizadas, plurais e diversas.

OTHER POSSIBLE SPEECHES: THE EMERGENCE OF THE PEOPLE'S COLLABORATIVE COMMUNICATION AS EDUCATIONAL STRATEGY 
ABSTRACT: In a world where the "discursive agendas" remain largely under the tutelage of a few, collaborative and popular communication as a form of educational resistance: as a "coup" against the dominant panoptic gaze of our society. The article argues that a new make communication is possible and, from another approach, referred to an educational communication, "other possible lines", built through a participatory model. Communication the position advocated by Serge Desgangné (2007), has the potential to offer a contribution to the subjects in a makeover open communication, which do not possess the "means of production" of accepted discourses become co- communicators and co-builders of their own opportunities.

KEYWORDS: Education. Educational practices. Popular communication. Collaborative communication.

\section{REFERÊNCIAS}

ASSOCIAÇÃO BRASILEIRA DE ORGANIZAÇÕES NÃO GOVERNAMENTAIS [ABONG]. O papel da sociedade civil nas novas pautas políticas. São Paulo: Pierópolis, 2004.

ADORNO. Theodor; HORKHEIMER, Max. Dialética do Esclarecimento: fragmentos filosóficos. Rio de Janeiro: Jorge Zahar, 1985.

BOAS, Frantz. Antropologia Cultural. 2. ed. Rio de Janeiro: Jorge Zahar, 2005.

BELTRÁN, Luís Ramiro. Adeus a Aristóteles: Comunicação Horizontal. Revista semestral de estudos de comunicação, São Paulo, v.3, n.6, p.5-37, 1981.

CERTEAU, Michel de. A invenção do cotidiano 1: Artes de fazer. 20. ed. Petrópolis: Vozes, 2013.

A cultura no Plural. Campinas: Papirus, 1995.

DEMO, Pedro. Educação e conhecimento: relação necessária, insuficiente e controversa. Petrópolis: Vozes, 2000.

DESGANGNÉ, Serge. O conceito de pesquisa colaborativa: a ideia de uma aproximação entre pesquisadores universitários e professores práticos. Revista Educação em Questão, Natal, v. 29, n. 15, p. 7-35, maio/ago. 2007.

FOUCAULT, Michel. A ordem do discurso. São Paulo: Loyola, 1999.

FERRARA, Lúcrécia D’Alessio. Olhar periférico: Informação, linguagem, percepção ambiental. São Paulo: EdUSP, 1993.

FREIRE, Paulo. Pedagogia do oprimido. Rio de Janeiro: Paz e Terra, 2005.

MACEDO. Roberto Sidnei. Outras Luzes: um rigor intercrítico para uma etnopesquisa política. In: MACEDO, Roberto Sidnei (Org.). Um rigor outro sobre a qualidade na pesquisa qualitativa: Educação e ciências antropossociais. Salvador: EDUFBA, 2009. p.75-126. 
MARTÍN-BARBERO, Jesús. Desafios culturais da comunicação à Educação. Revista Comunicação \& Educação, São Paulo, v. 181, p.51-61, 2000.

MENDONÇA. Maria Luiza Martins. Processos Comunicativos e subjetividade: desafios para o terceiro Setor. Comunicação e Política, Rio de Janeiro, v.22, n.3, p.49-64, 2004.

MORIN, Edgar. Introdução ao pensamento complexo. Porto Alegre: Sulina, 2005.

MOURA, Abdalazis de. Filosofia e Princípios da PEADS (PE) e do CAT (BA). In: BAPTISTA, Francisca Maria Carneiro; BAPTISTA, Naidison de Quintela (Org.). Educação Rural: sustentabilidade do Campo. Feira de Santana, BA: MOC: UEFS: SERTA (PE), 2003. p.16-52.

PERUZZO, Cicília Maria Krohling. Revisitando os conceitos de comunicação popular, alternativa e comunitária. In: CONGRESSO BRASILEIRO DE CIÊNCIAS DA COMUNICAÇÃO, 29., 2006, Brasília. Anais... Brasília: Intercom, 2006. p.1-17.

SANTOS, Maria Salett Tauk. Comunicação participativa e ação libertadora: marxismo e cristianismo combinados na teoria da comunicação dos anos 70 e 80. 2002. Disponível em:

<http://www.paulofreire.ufpb.br/paulofreire/Files/seminarios/oral36.pdf>. Acesso em: $02 / 12 / 2014$.

SANTOS, Milton. Por uma outra globalização: do pensamento único a consciência universal. Rio de Janeiro: Record, 2011.

SOARES, Ismar Oliveira de. Educomunicação: um campo de mediações. Revista Comunicação \& Educação, São Paulo, v.19, p.12-24, set./dez. 2000.

WOLF, Mauro. Teorias da comunicação. Lisboa: Editorial Presença, 1999. 